\title{
The Index of Evidence: speculative methodologies in response
} to the post-truth era [version 1; peer review: 1 approved with reservations, 2 not approved]

\section{Gill Partington (D), Laura Salisbury (D), Steve Hinchliffe, Mike Michael, Lara Choksey}

University of Exeter, Exeter, UK

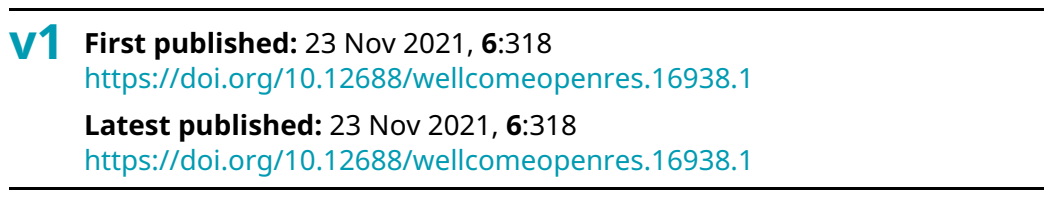

\section{Abstract}

The past year has shown that even the fundamental idea of 'evidence' - in health contexts, but also more broadly - is coming under increasing strain. This open letter argues that the current crises of evidence and knowledge in which we find ourselves demands new speculative methodologies. It introduces the Index of Evidence - a Beacon Project funded by Exeter University's Wellcome Centre for Cultures and Environments of Health - as one example of such a methodology, outlining its theoretical foundations and process. The key innovation of this project is to rethink the form and presentation that research can take. Using the conceptual and material affordances of the index, it merges the creative and critical in ways that aim to make an important contribution to more inter-connected, theoretically sophisticated thinking around evidence.

\section{Keywords}

Evidence, Fact, Methodology, Index, Creative-Critical

Open Peer Review
Approval Status X $\times$ ?
version 1
Evidence Centre for Education, Durham, UK
Seoul, South Korea
3. Ilana Löwy (iD), CERMES 3 (INSERM, CNRS,
EHESS, Paris V University), Villejuif, France
Any reports and responses or comments on the
article can be found at the end of the article.


Corresponding author: Gill Partington (gillpartington@gmail.com)

Author roles: Partington G: Conceptualization, Investigation, Methodology, Project Administration, Writing - Original Draft Preparation; Salisbury L: Conceptualization, Funding Acquisition, Investigation, Methodology, Project Administration, Writing - Review \& Editing; Hinchliffe S: Conceptualization, Funding Acquisition, Investigation, Methodology, Project Administration, Writing - Review \& Editing; Michael M: Conceptualization, Funding Acquisition, Investigation, Methodology, Project Administration, Writing - Review \& Editing; Choksey L: Conceptualization, Investigation, Methodology, Project Administration, Writing - Review \& Editing

Competing interests: No competing interests were disclosed.

Grant information: This work was supported by the Wellcome Trust [203109].

Copyright: (c) 2021 Partington G et al. This is an open access article distributed under the terms of the Creative Commons Attribution License, which permits unrestricted use, distribution, and reproduction in any medium, provided the original work is properly cited.

How to cite this article: Partington G, Salisbury L, Hinchliffe $S$ et al. The Index of Evidence: speculative methodologies in response to the post-truth era [version 1; peer review: 1 approved with reservations, 2 not approved] Wellcome Open Research 2021, 6:318 https://doi.org/10.12688/wellcomeopenres.16938.1

First published: 23 Nov 2021, 6:318 https://doi.org/10.12688/wellcomeopenres.16938.1 


\section{Introduction}

The coronavirus disease 2019 (COVID-19) pandemic has presented itself as an epistemological as well as an epidemiological crisis, demonstrating just how fraught and contested questions of evidence have now become ${ }^{1}$. Most obviously, it has highlighted the degree to which trust in top-down expertise has fractured, and the growing power of social media to generate what the World Health Organisation (WHO) dubbed an 'infodemic'? widespread misinformation, false claims and conspiracy theories about the causes of COVID-19, remedies, vaccination, mask-wearing $\mathrm{etc}^{3}$. But, at a more fundamental level, it has brought the very notion of evidence itself into question, exposing its equivocality, fault-lines and complexities. Despite the government mantra, 'following the science' has never seemed less simple or straightforward. What are the processes through which raw data (assuming such a thing exists) is translated into usable evidence, into epidemiological models, or narrative shape? And if disciplines and fields of knowledge construct and mobilise evidence differently, how do we negotiate between these sometimes incommensurate forms? What of the relationship between scientific expertise (be it from laboratories, in silica models, various disciplines, or advisory panels), clinical or practice-based insights, and the first-hand experience of patients? Who decides what kinds of evidence counts? How can evidence be effectively mobilised in our current, post-truth context, while still acknowledging its limitations or incompleteness?

Understanding how these challenges are being felt in health contexts should be a priority for the medical humanities and social sciences, but they are by definition complex, broad-based phenomena, scattered across multiple cultural locations and diagnosed under a shifting set of terms: the 'post-factual' ${ }^{4}$, the misinformation society', "fake news' ${ }^{6}$, 'information disorder' and that most widespread neologism, 'post-truth' ${ }^{8}$. New kinds of methodology are needed, capable of thinking across disciplinary and cultural boundaries, but also across media. In this Open Letter, we introduce one such response to this problem - the Index of Evidence - a Beacon Project situated in the Wellcome Centre for Cultures and Environments of Health at the University of Exeter. As the interdisciplinary group of scholars leading the project, we explain the rationale behind this unusual and exploratory initiative, which approaches these 21 st century questions and contexts of evidence by repurposing a distinctly old-fashioned print device. It puts the alphabetical index to creative use as the starting point for a co-authored, open-ended and evolving text. While a definitive account of our current upheavals can't yet be written, this index is instead a work in progress. It traces the shifting dynamics of evidence, mapping the connections and disjunctions between disparate kinds of knowledge, tracing and materialising an emergent network of new concepts, terminologies and ways of thinking.

\section{Overview}

The Index of Evidence is an initiative begun in late 2019 that entails an exploration of the ways evidence is constituted, contested, mobilised or undermined - in relation to the formation of 'Healthy Publics". The project recognises that we are in a historical, socio-cultural, material and political moment where the question of what constitutes a 'fact' and how evidence might legitimately be used to address health problems has come to a point of crisis $^{10}$. While the task of understanding, mapping and intervening in this situation is an urgent one, the question of how it should be approached is complex and difficult. The dangers of health misinformation and misleading evidence have been widely recognised and analysed, as has its remarkable resistance to disproof, refutation or debunking ${ }^{11,12}$. This project is an intervention of a different kind, however. Instead of adding to an already burgeoning literature on evidence in theoretical or socio-historical terms ${ }^{13}$, or simply attempting to shore up the truth status of scientific facts, it is a performative response to the complex terrain in which we find ourselves. It unfolds the new ontology of evidence using more formally innovative and speculative methods. It begins with the index to an imagined, but unwritten book. It invites academics in diverse disciplines as well as non-academic publics to respond to its entries, encouraging them to follow and elaborate on their own areas of interest, to think in both disciplinary and in speculative ways, and to value and use multiple registers and voices.

The Index of Evidence is thus a decentred, multi-authored text-in process. Its online index terms link to short entries that unpack particular corners, lines, or questions of evidence. Some entries seem obvious: 'alternative facts'; 'evidence-based medicine'; 'big data'; 'qualitative'; 'quantitative'; 'randomised control trial'; 'vaccination'. Others are much more unexpected and speculative: 'genre'; 'badgers'; 'gold'; 'anomaly'; 'pattern'; 'circumcision'. The index allows readers to take unexpected journeys, piecing together a picture of what is happening to evidence across a range of cultural contexts, from online populism and social media controversies to institutional and scientific debate. It explores what forms evidence now takes, the terminology and concepts that surround it, and the ways it is mobilised and circulated. The Index of Evidence is a tool for orientating and disorientating ourselves within this new territory. It explores our predicament from fresh angles, asking what new understanding might be gained from recent upheavals, and what routes forward can be plotted. It aims to become both an example of and resource for thinking about the intersecting complexity of evidence, alongside the affective and conceptual bonds that are involved in the formation of healthy (and sometimes unhealthy) publics. The index will necessarily remain unfinished and will have a lifespan beyond the funding period for the Wellcome Centre for the Cultures and Environments of Health.

\section{Theoretical contexts}

Responses to the destabilisation of fact and evidence from scholars and those working in health contexts have typically taken one of three forms: 'big data' studies analysing the scale and nature of the problem ${ }^{14}$, polemics railing against pseudoscience or irrationality ${ }^{15}$, or direct, localised fact-checking interventions intended to combat online misinformation ${ }^{16}$. The Index of Evidence approaches this problem from a different 
angle, deploying the insights of cultural and critical theory to better understand the new ontology of evidence. It takes its cue from theoretical work in the humanities and social sciences that allows for more speculative thinking about evidence, and ways to model its relations, associations, and patterns. The project is informed firstly by Latourian ideas of the network - the idea that knowledge is produced through the interplay of actors, both human and non-human, through material and media objects ${ }^{17}$. Secondly, we attend also to Michel Serres's notion of the passage between, and the complex, twisting topologies that can connect apparently distant points ${ }^{18}$, and thirdly to the concept of the rhizome, as elaborated by Gilles Deleuze and Felix Guattari ${ }^{19}$. A rhizome resists the arborescent (root and branch) model or organisation, where causality can be pursued in chronological terms to an origin or where there is a teleological movement towards a conclusion. Instead, a rhizome resists the genealogical - it also resists the idea of a centre - to present a flat landscape which presents the possibility of all points connecting to all others on one plane. In Deleuze and Guattari's terms: 'A rhizome has no beginning or end; it is always in the middle, between things, interbeing, intermezzo. The tree is filiation, but the rhizome is alliance' ${ }^{20}$. In its online form, the Index of Evidence might be said to resemble a rhizomatic structure in its possibility of multiplicity; its not-completely rather than absolutely non-hierarchical entry and exit points; and its demand for non-linear writing and reading strategies that represent and subsequently interpret the data it gathers.

Equally importantly, the project draws on historians of the book and information, who have highlighted how evidence and fact have always been shaped by technologies of media and communication, well before the advent of social media. Adrian Johns shows how the authority of factual knowledge in print was hard-won, constructed through the book's conventions, its presentation and material organisation ${ }^{21}$. Ann Blair and Anthony Grafton have examined the history of the book's referencing conventions and footnotes - the paratextual apparatuses which function not only to order information but also as forms of evidence in themselves, tools to authorise and codify disciplinary knowledge ${ }^{22,23}$. The index is one of the most fundamental of these print ordering devices, as Dennis Duncan has shown, one which not only enabled the printed book to be used as resource of factual knowledge, a reference work for information, but also - more indirectly - as a signifier of reliable knowledge itself ${ }^{24}$.

\section{The index as method}

This project appropriates the index creatively, as a genre of writing: one that presents possibilities that a conventional scholarly book or article cannot. The term index itself derives from the Latin verb indicare or 'indicate.' It designates a sign or measure of something, a device that points towards a particular page, allowing you to find your way around quickly and easily. Traditionally, the index oriented readers in a world of printed fact, but this one is different. It explores how we might find our way through the shifting, uncertain terrain of a multi-media digital era. And while a conventional index is the last word to a book, compiled only after the text has been written, this one is only the starting point. The Index of Evidence begins with a list of terms that resonate in the contemporary moment. These are terms which recur around questions of evidence in science, medicine and academic debate, but also in popular culture and on social media. Cumulatively, they may suggest the ways knowledge is being transformed. But initially they are entries that point nowhere. They are an index to a book about evidence, but one that has yet to be written.

The Index of Evidence exploits and subverts the potential of the index as a form. On the one hand, it initially appears to be a highly disciplined object, promising order and completeness, and providing orientation around a known terrain. But on the other, it produces its own powerfully excessive operations and translations. The index scrambles the linearity of a book, rendering visible new points and practices of contact between knowledges and ways of knowing. As Dennis Duncan notes in his forthcoming book on the topic, 'the chief mechanism of the index is its arbitrariness in relation to the work' ${ }^{25}$. It allows things that might seem conceptually far apart to be rendered suddenly and unexpectedly proximate, therefore exceeding the reader's intentions too. An index allows 'deconstruction' to sit blithely next to 'dialectic'; 'ethics' to cosy up to 'eugenics'; 'habit' to be visually linked to 'Holocaust'; while prompting the reader to join the dots of the relation between the terms. This index uses these aleatory qualities of alphabetisation and the non-linearity of a digital environment to suggest that we are always in the middle of things when we aim to understand and use evidence.

In strategically repurposing this print codex device, the Index of Evidence follows the example set by writers and artists who have appropriated it playfully, showing that the index can be a powerful device, with the capacity to point us in new directions, send us on unexpected journeys of discovery, or tell us things that the main text itself cannot. Mark Danielewski's House of Leaves (2000) and Vladimir Nabokov's Pale Fire (1962) are novels that use indexes to distinctive rhetorical effect, operating as part of their elaborate narrative games ${ }^{26,27}$. Artists, too, have put it to new uses. Nick Thurston has republished the index to Nietzsche's Gay Science as a standalone text $\mathrm{t}^{28}$, and Alejandro Cesarco produces indexes to imaginary books ${ }^{29}$. In these cases it becomes an oddly suggestive and poetic form, telling stories of its own.

We deploy an analogous creative strategy in the current, uncertain context of evidence. What can the index do that more orthodox academic argument or refutation cannot? What can its workings tell us about the processes through which we filter information, choosing what - or whom - to trust? What can it reveal about how evidence is produced and 
how it gains traction? What effect does its disconcerting shift from page to screen have? By thinking together about these issues we aim to create an evolving map of evidence.

\section{Process}

Simply put, the Index of Evidence is an online text. It began as merely a list of words - an index of terms that pointed nowhere. Over the course of the project, contributors from diverse disciplines and fields of expertise have been invited to respond to one or more of these index terms, or 'heads'. At the time of writing there are nearly 40 such contributions from established academics, early career researchers, artists, health advocates and other stakeholders. The index has a global perspective, with contributions drawn from institutions as far apart as India and the USA, and varies widely in terms of register and style. Its contributions are sometimes dense and scholarly, and sometimes more provocative, elliptical and creative. They incorporate not only text but visual material, audio recordings of oral testimony. They can be brief thoughts, anecdotes, images, diagrams, sound and video. The Index of Evidence is thus a collaborative project, a text that is collectively written, dispersed, fragmented and on-going, incorporating diverse voices and viewpoints and ways of writing.

These parts do not - and are not intended to - add up to a whole, however. Instead, the index is an ever-evolving, incomplete picture of our new situation. Just as in a conventional index, there are page numbers pointing the reader to a destination (but not necessarily where they expected), and from there, they can follow other, sideways chains of links to explore a network of other, related terms and their meanings. But as hyperlinks, these page numbers also point playfully to the incommensurable logic of page and screen. A 'book' of sorts is taking shape around the index, but unlike a print book it can never be assembled in the correct order, or read sequentially. It is virtual, open-ended and necessarily unfinished. From a user perspective, the index is an interactive tool, inviting readers to explore and reflect on how they navigate their way through information - what links they follow, what kinds of signals, cues and paratexts lead them to trust or mistrust, believe or disbelieve.

Most crucially, the index is a research methodology that is fundamentally iterative. Its logic is emergent and contingent rather than pre-planned or encyclopaedic, and its rules and conventions are still developing in response to the new entries added. As the work on the building of the Index of Evidence has shown, the index as object (which is also, necessarily, the index as practice or strategy), permits the map to become the process of the passage. Although it began in the months before the current health crisis, it has been caught up in the middle of it, responding in real time to the unfolding debates around evidence and health. This responsiveness and ability to develop in relation to ongoing events is the index's major advantage. Its entries reveal how far the terms 'COVID-19' and 'pandemic' and 'virus' have come to intersect with existing concerns about evidence.

\section{Conclusion}

The Index of Evidence puts the navigational tool of the print index back into play in the unbound, networked environment of the internet to see where it leads us. It thinks about how to respond to the seeming crisis of evidence without simply replicating the narrative structure of crisis itself. The project asks what new understanding might be gained from recent upheavals, and what routes forward can be plotted. Its aim, ultimately, is to assemble a new public around the question of evidence - one that will model the diverse and the sometimes contradictory voices needed to take account of the complexity of how evidence comes to be constituted as such and then used to make decisions about health.

\section{Data availability}

No data are associated with this article.
1. Beer FA, Hariman R: Learning from the Pandemic: Catastrophic Epistemology. Social Epistemology Review and Reply Collective. 2020; 9(5): 19-28. Reference Source

2. https://www.who.int/docs/default-source/coronaviruse/situationreports/20200202-sitrep-13-ncov-v3.pdf?sfvrsn=195f4010 6

3. Garrett L: COVID-19: the medium is the message. Lancet. 2020; 395(10228): 942-943.

PubMed Abstract | Publisher Full Text | Free Full Text

4. Berling T, Bueger C: Expertise in the Age of Post-Factual politics: An outline of reflexive strategies. Geoforum. 2017; 84: 332-341. Publisher Full Text

5. Pickard V: The Big Picture: Misinformation Society. Public Books. (blog) 2017 Reference Source

6. Lazer DMJ, Baum MA, Benkler Y, et al.: The Science of Fake News. Science. 2018; 359(6380): 1094-96

PubMed Abstract | Publisher Full Text

7. Wardle C, Derakhshan H: Information disorder: Toward an interdisciplinary framework for research and policy making. [Council of Europe policy report
DGI(2017)09, Council of Europe, 2017].

Reference Source

8. Sismondo S: Post-Truth? Soc Stud Sci. 2017; 47(1): 3-6. PubMed Abstract | Publisher Full Text

9. Hinchliffe $S$, Jackson MA, Wyatt $K$, et al:: Healthy publics: enabling cultures and environments for health. Palgrave Commun. 2018; 4: 57. PubMed Abstract | Publisher Full Text | Free Full Text

10. Kelly AH, McGoey L: Facts, power and global evidence: a new empire of truth. Economy and Society. 2018; 47(1): 1-26. Publisher Full Text

11. van der Meer TGLA, Jin Y: Seeking Formula for Misinformation Treatment in Public Health Crises: The Effects of Corrective Information Type and Source. Health Commun. 2020; 35(5): 560-575. PubMed Abstract | Publisher Full Text

12. Ecker UKH, Lewandowsky $S$, Chadwick M: Can corrections spread misinformation to new audiences? Testing for the elusive familiarity backfire effect. Cogn Res Princ Implic. 2020; 5(1): 41. PubMed Abstract | Publisher Full Text | Free Full Text 
13. Starbird K, Spiro ES, Koltai K: Misinformation, Crisis, and Public HealthReviewing the Literature. MediaWell. 2020. Jasanoff, Sheila, and Hilton R. Simmet. 2017. "No Funeral Bells: Public Reason in a 'Post-Truth' Age." Social Studies of Science, vol. 47, no. 5, pp. 751-770, doi:10.1177/0306312717731936; Chaudhary, Zahid R. 2020. "The Politics of Exposure: Truth After Post-Facts."

ELH, vol. 87 no. 2, p. 301-324. doi:10.1353/elh.2020.0020; Aradau, Claudia, and Jef Huysmans. 2019. "Assembling Credibility: Knowledge, Method and Critique in Times of 'Post-Truth."' Security Dialogue, vol. 50, no. 1, pp. 40-58, doi:10.117 7/0967010618788996; Harsin, J. 2015. "Regimes of Post-truth, Post-politics, and Attention Economies. Communication." Culture \& Critique, 8: 327-333. doi.org/10.1111/cccr.12097. Publisher Full Text

14. See the current international AHRC funded project analysing the circulation of online COVID-19 related conspiracy theories 'Comparative Analysis of Conspiracy Theories (COMPACT). Reference Source

15. Heinrich S: Medical Science Faces the Post-Truth era: a Plea for the Grassroot Values of Science. Curr Opin Anaesthesiol. 2020: 33(2): 198-202. Gawande, Atul. 'The Mistrust of Science'. The New Yorker. https://www. newyorker.com/news/news-desk/the-mistrust-of-science. Accessed $12 \mathrm{Mar}$ 2021.

PubMed Abstract | Publisher Full Text

16. See the recently established fact-checking initiative run by King's College London. Reference Source

17. Latour B: Reassembling the Social: An Introduction to Actor-Network-Theory. New edition, Oxford University Press, USA, 2007.

Reference Source
18. Serres M: Hermes: Literature, Science, Philosophy. New edition, The Johns Hopkins University Press, 1983. Reference Source

19. Deleuze G, Guattari F: EPZ Thousand Plateaus. A\&C Black, 2004. Reference Source

20. Deleuze, Guattari: 25 .

21. Johns A: The Nature of the Book: Print and Knowledge in the Making. Chicago: University of Chicago Press, 2000. Reference Source

22. Blair AM: Too Much to Know: Managing Scholarly Information before the Modern Age. New Haven: Yale University Press, 2011 Reference Source

23. Grafton A: The Footnote - A Curious History. Cambridge, Mass.: Harvard University Press, 1999. Reference Source

24. Duncan D: Index, A History of The. London: Allen Lane, 2021. Reference Source

26. Danielewski MZ, Zampanò, Truant J: Mark Z. Danielewski's House of Leaves. 2000.

Reference Source

27. Nabokov VV: Pale Fire: A Novel. 1962. Reference Source

28. Thurston N: Historia Abscondita or Index of Joy. York: Information as Material, 2007. Reference Source

29. http://cesarco.info/\#index-an-orphan 


\section{Open Peer Review}

\section{Current Peer Review Status: $\mathrm{X} \times$}

Version 1

Reviewer Report 13 April 2022

https://doi.org/10.21956/wellcomeopenres.18691.r49229

(C) 2022 Löwy I. This is an open access peer review report distributed under the terms of the Creative Commons Attribution License, which permits unrestricted use, distribution, and reproduction in any medium, provided the original work is properly cited.

\section{Ilana Löwy \\ CERMES 3 (INSERM, CNRS, EHESS, Paris V University), Villejuif, France}

The declared aim of the open letter, "The Index of Evidence: speculative methodologies in response to the post-truth era" is to provide an innovative way to grapple with the recent crisis of "evidence" and "knowledge:" construction of a new methodology to evaluate evidence, the Index of Evidence. This methodology, the authors claim, provides interconnected and theoretically sophisticated thinking around evidence.

The main difficulty with this text is that it addresses two very different issues. One is the "crisis of evidence", especially as revealed by Covid-19 pandemics. This issue can be linked to the broader theme of uses and misuses of scientific expertise and tensions between groups of stakeholders who apply scientific knowledge in different contexts. Crisis of evidence was discussed by numerous sociologists and anthropologists; among others Gil Eyal, The Crisis of Expertise, (Polity Press, 2019) .https://www.politybooks.com/bookdetail?book_slug=the-crisis-of-expertise-9780745665771

or the ongoing investigation of the MPIWG research group "Practices of validation in the biomedical sciences."

https://www.mpiwg-berlin.mpg.de/feature-story/practices-validation-biomedical-sciences

The second issue is the use of an open-ended index as a new source of knowledge. The open letter advocates the construction of non-structured indexes that mix "obvious" and "unexpected/ speculative" terms, and produces a tool "for orienting and disorienting ourselves." This free form of creativity draws on elements borrowed from cultural studies of indexation, novels that use the "imaginary index" as a device of alluding to imaginary entities, and philosophical studies that attempted to describe complex, multilevel, and open-ended situations. Such use of an index is an intriguing and potentially stimulating idea. However, the manuscript does not clarify how studies by historians of the book who investigated the role of indexing and footnoting in the production of knowledge are linked to literary experiments and elaborate narrative games, or how the second part of the text that discusses creative indexes is articulated with the first part that discusses the authority of evidence-producing devices. 
I tried, following the author's guidance, to construct an index to their text: Baconian project, Covid19, code, creative strategy, disorienting, evidence, expertise, footnote, hyperlink, index, in-silica models, intermezzo, narrative games, navigation, network, predicament, provocation, topology, trust, rhizome, WHO. Such an index may be described as playful, elliptical, and creative, but I am less sure that it helps to understand what evidence is.

Because of the complexity of the discussed issues, and since one of the problems of this manuscript is the difficulty to define precisely what the main question is and how it should be answered, the criteria proposed by Wellcome Open to judge their manuscript: a) "Is the rationale for the Open Letter provided in sufficient detail? “b) "Does the article adequately reference differing views and opinions? " and c) Are all factual statements correct, and are statements and arguments made adequately supported by citations? " are not well adapted to describe this text's strengths and weaknesses.

Is the rationale for the Open Letter provided in sufficient detail? Partly

Does the article adequately reference differing views and opinions? Partly

Are all factual statements correct, and are statements and arguments made adequately supported by citations?

Partly

Is the Open Letter written in accessible language?

Yes

Where applicable, are recommendations and next steps explained clearly for others to follow?

Not applicable

Competing Interests: No competing interests were disclosed.

Reviewer Expertise: History of science and medicine.

I confirm that I have read this submission and believe that I have an appropriate level of expertise to confirm that it is of an acceptable scientific standard, however I have significant reservations, as outlined above.

Author Response 05 May 2022

Laura Salisbury, University of Exeter, Exeter, UK

We thank the three reviewers for responding to the Open letter. They make important points about the heightened stakes in relation to evidence, the audience for humanities and social science interventions on contested topics, and the geographical scope of contributions for thinking about the nature of evidence. We agree with these points and 
would suggest that they inform key debates to which this project can and should continue to contribute.

The project started just before the COVID-19 pandemic and was somewhat overtaken by events as the issue of science informing policy became once again critical. The battles over what forms of evidence count, how evidence is often selectively presented and produces particular effects as it is circulated and consumed (or reduced and dismissed), have become central to how the pandemic and its aftermath have been experienced.

The key point of the Index and the collected texts (which can and should continue to grow) was not to provide definitive solutions to the question of evidence, nor was it to question the importance of evidence (or undermine the purpose of evidence-based policy). Instead, our aim was to highlight the diversity of data and methods that need to be brought together and thought alongside one another in order to construct good evidence. The project is necessarily emergent and has sought to allow contributors and readers to speculate on how re-thinking evidence (as a practice) might open up new opportunities for doing better work, for bringing narrative together with extensive data sets, for taking nonhierarchical approaches to data sources and forms, and in the process assembling new kinds of insight (something that clinicians regularly do in their day-to-day practice, for example). This was about opening up rather than closing things down, but, importantly, opening up in a more speculative way. Speculation has allowed writers the option to invent new ways of thinking about evidence - its production and relations. It bears repeating that the invitation of the project was not a way of suggesting that evidence is simply invented, but that we might discover new ways of producing better evidence and better relationships to evidence by loosening, temporarily, some of hierarchies and disciplinary forms that determine what can be indexed as evidence.

As the pandemic has developed, we have begun to see the Index as a space that might also track circulations of data and their appropriations. But the project's aim was never to argue particular points of evidence; rather, it was to stimulate interest in and increase understanding of how evidence emerges according to particular patterns and practices. While contributors are, as far as we can tell, committed to the shared project of improving how we think and do evidence, we felt it important to encourage them to experiment with the form and style of their contributions in order to open up the possibility of thinking and practising evidence otherwise. The team behind the Index of Evidence decided that it was important to peer review the contributions, however, to ensure that misinformation, disinformation, or points that were easily open to misinterpretation did not damage the scene of legitimate evidence.

So, the contributions are not about undermining the idea of evidence but finding ways to think about the problems of evidence: how to assemble it, how to narrate it, and how to protect it. The overarching theme of engaging with evidence as a concept and set of relations has meant that so far those most interested in contributing have been academic researchers. Contributors, some of whom are in earlier stages of their careers, have been enabled to write with a degree of experimental openness and frankness, without following conventional forms. While this open authorship, and the suggested openness to reading the entries, may be risky, given the stakes, we took the decision to retain an experimental 
feel to the Index rather than pre-script its outputs, intents, and audiences. True, the results may at this stage remain overly academic and are certainly geographically limited, but we hope that the Index can still raise some questions and perhaps offer glimpses of what an open assembly on evidence could produce. Part of the rationale for publishing an Open Letter was to introduce the project to a wider audience of potentially interested readers and contributors. The conceptual work to determine what can be learned from how the Index has developed - its successes and also its failures - will necessarily need to come later.

Given the nature of the letter and the intention of the work, which was to index a collective project on the fraught nature of evidence, we don't think it is useful at this stage to revise the text; doing so would be unlikely to resolve the valid reservations expressed concerning stakes, audience, and scope. And, as one of the reviewers notes, the nature of this piece was not well-fitted to the Wellcome Open's criteria of a) "Is the rationale for the Open Letter provided in sufficient detail? "b) "Does the article adequately reference differing views and opinions?" and c) Are all factual statements correct, and are statements and arguments made adequately supported by citations?" So rather than revise our original piece, we would hope that these views can instead be read alongside the Index and be used to stimulate more thoughts on the ways in which evidence might be assembled in future.

The Index of Evidence can be found at: https://www.indexofevidence.org

Steve Hinchliffe, Mike Michael, Laura Salisbury

Competing Interests: No competing interests were disclosed.

Reviewer Report 11 April 2022

https://doi.org/10.21956/wellcomeopenres.18691.r49228

(c) 2022 Holman B. This is an open access peer review report distributed under the terms of the Creative Commons Attribution License, which permits unrestricted use, distribution, and reproduction in any medium, provided the original work is properly cited.

\section{Bennett Holman}

Underwood International College, Yonsei University, Seoul, South Korea

I am firmly of the view that those who have specialized in the construction of knowledge may be well-posed to help society come to a better understanding of knowledge. The issue the open letter fails to make clear is who is the index for and what impact does it aim to achieve? Failing a clear articulation of the scope of the project, it is difficult to assess.

As it stands it appears to be a (chiefly) British endeavor (the choice to highlight Indian and American contributors is misleading and not terribly good form in a project about misinformation) written by and presumably for a (chiefly) scholarly audience enmeshed in the science and technology studies literature. If the project aims to be a semi-formal means for such scholars to 
exchange ideas then the project might well serve as an interesting alternative means of communication that is less formal than a journal and more integrated than a blog post. But if it means to reach outside that circle of scholars it seems poorly situated to do so.

The team would seem to lack researchers that are primarily involved in the medical/health research (rather than scholars of the production of that work) and it is unclear whether such researchers would find the material useful or be inclined to engage with the project. Why, for example, would an expert inclined to such a collaborative project not spend their time contributing to the Wikipedia page?

Similarly, the index is not well positioned to make a direct contribution to the problems that ostensibly prompt it (i.e., the infodemic, rise of post-truth, etc.). It seems unlikely that a member of the public that is inclined to accept a misleading Facebook post that "COVID vaccines will change your DNA" (they will not) is going to be a new view of the production of scientific knowledge from engaging with the index. Indeed, it seems like just the sort of jargon-laden writing that a posttruther would perceive as "elitist academic musings" and reflexively reject.

Which, again, is all a matter of aim. Increased clarity on who is the "new public" the project aims to create and by what standards they would judge the project to be successful would go a long way to clarify whether the project is well-targeted. To the extent that the project aims to address the problems of post-truth, misinformation, etc. indirectly by cross-pollinating ideas in the sphere of Science and Technology Studies, the project seems to be off to a good start. To the extent it aims to engage more broadly or have a more direct impact, it is far less clear how it is positioned to do so.

Is the rationale for the Open Letter provided in sufficient detail? No

Does the article adequately reference differing views and opinions? Yes

Are all factual statements correct, and are statements and arguments made adequately supported by citations?

Yes

Is the Open Letter written in accessible language?

Partly

Where applicable, are recommendations and next steps explained clearly for others to follow?

Yes

Competing Interests: No competing interests were disclosed.

Reviewer Expertise: History and Philosophy of Medicine, Science and Values, Political Polarization

I confirm that I have read this submission and believe that I have an appropriate level of 


\section{expertise to state that I do not consider it to be of an acceptable scientific standard, for reasons outlined above.}

Author Response 05 May 2022

Laura Salisbury, University of Exeter, Exeter, UK

We thank the three reviewers for responding to the Open letter. They make important points about the heightened stakes in relation to evidence, the audience for humanities and social science interventions on contested topics, and the geographical scope of contributions for thinking about the nature of evidence. We agree with these points and would suggest that they inform key debates to which this project can and should continue to contribute.

The project started just before the COVID-19 pandemic and was somewhat overtaken by events as the issue of science informing policy became once again critical. The battles over what forms of evidence count, how evidence is often selectively presented and produces particular effects as it is circulated and consumed (or reduced and dismissed), have become central to how the pandemic and its aftermath have been experienced.

The key point of the Index and the collected texts (which can and should continue to grow) was not to provide definitive solutions to the question of evidence, nor was it to question the importance of evidence (or undermine the purpose of evidence-based policy). Instead, our aim was to highlight the diversity of data and methods that need to be brought together and thought alongside one another in order to construct good evidence. The project is necessarily emergent and has sought to allow contributors and readers to speculate on how re-thinking evidence (as a practice) might open up new opportunities for doing better work, for bringing narrative together with extensive data sets, for taking nonhierarchical approaches to data sources and forms, and in the process assembling new kinds of insight (something that clinicians regularly do in their day-to-day practice, for example). This was about opening up rather than closing things down, but, importantly, opening up in a more speculative way. Speculation has allowed writers the option to invent new ways of thinking about evidence - its production and relations. It bears repeating that the invitation of the project was not a way of suggesting that evidence is simply invented, but that we might discover new ways of producing better evidence and better relationships to evidence by loosening, temporarily, some of hierarchies and disciplinary forms that determine what can be indexed as evidence.

As the pandemic has developed, we have begun to see the Index as a space that might also track circulations of data and their appropriations. But the project's aim was never to argue particular points of evidence; rather, it was to stimulate interest in and increase understanding of how evidence emerges according to particular patterns and practices. While contributors are, as far as we can tell, committed to the shared project of improving how we think and do evidence, we felt it important to encourage them to experiment with the form and style of their contributions in order to open up the possibility of thinking and practising evidence otherwise. The team behind the Index of Evidence decided that it was important to peer review the contributions, however, to ensure that misinformation, disinformation, or points that were easily open to misinterpretation did not damage the 
scene of legitimate evidence.

So, the contributions are not about undermining the idea of evidence but finding ways to think about the problems of evidence: how to assemble it, how to narrate it, and how to protect it. The overarching theme of engaging with evidence as a concept and set of relations has meant that so far those most interested in contributing have been academic researchers. Contributors, some of whom are in earlier stages of their careers, have been enabled to write with a degree of experimental openness and frankness, without following conventional forms. While this open authorship, and the suggested openness to reading the entries, may be risky, given the stakes, we took the decision to retain an experimental feel to the Index rather than pre-script its outputs, intents, and audiences. True, the results may at this stage remain overly academic and are certainly geographically limited, but we hope that the Index can still raise some questions and perhaps offer glimpses of what an open assembly on evidence could produce. Part of the rationale for publishing an Open Letter was to introduce the project to a wider audience of potentially interested readers and contributors. The conceptual work to determine what can be learned from how the Index has developed - its successes and also its failures - will necessarily need to come later.

Given the nature of the letter and the intention of the work, which was to index a collective project on the fraught nature of evidence, we don't think it is useful at this stage to revise the text; doing so would be unlikely to resolve the valid reservations expressed concerning stakes, audience, and scope. And, as one of the reviewers notes, the nature of this piece was not well-fitted to the Wellcome Open's criteria of a) "Is the rationale for the Open Letter provided in sufficient detail? "b) "Does the article adequately reference differing views and opinions?" and c) Are all factual statements correct, and are statements and arguments made adequately supported by citations?" So rather than revise our original piece, we would hope that these views can instead be read alongside the Index and be used to stimulate more thoughts on the ways in which evidence might be assembled in future.

The Index of Evidence can be found at: https://www.indexofevidence.org

Steve Hinchliffe, Mike Michael, Laura Salisbury

Competing Interests: No competing interests were disclosed.

Reviewer Report 26 November 2021

https://doi.org/10.21956/wellcomeopenres.18691.r47181

(C) 2021 Gorard S. This is an open access peer review report distributed under the terms of the Creative Commons Attribution License, which permits unrestricted use, distribution, and reproduction in any medium, provided the original work is properly cited.

Stephen Gorard 
Durham University Evidence Centre for Education, Durham, UK

The paper is insubstantial. It states in the title that it is about an "Index of Evidence" but nowhere states clearly what that is. It appears to be a list of 40 terms that may have something to do with evidence.

The abstract gives no clear summary of an argument, proposition, or of research.

The reader needs to know at the outset exactly what this index is, and how it is considered to address the issue of false claims.

The paper, especially on page 2, appears to confuse false/fake claims (undesirable) with disputed claims on the basis of evidence (an important part of social science).

By the end of the paper, it is still no clearer what the index is and how it might be useful.

The paper would need to be completely rewritten to be clear to a reader, assuming that there is indeed anything of substance here at all.

Is the rationale for the Open Letter provided in sufficient detail?

No

Does the article adequately reference differing views and opinions?

No

Are all factual statements correct, and are statements and arguments made adequately supported by citations?

No

Is the Open Letter written in accessible language?

No

Where applicable, are recommendations and next steps explained clearly for others to follow?

No

Competing Interests: No competing interests were disclosed.

Reviewer Expertise: Social science research methods, and the use of evidence.

I confirm that I have read this submission and believe that I have an appropriate level of expertise to state that I do not consider it to be of an acceptable scientific standard, for reasons outlined above. 
Laura Salisbury, University of Exeter, Exeter, UK

We thank the three reviewers for responding to the Open letter. They make important points about the heightened stakes in relation to evidence, the audience for humanities and social science interventions on contested topics, and the geographical scope of contributions for thinking about the nature of evidence. We agree with these points and would suggest that they inform key debates to which this project can and should continue to contribute.

The project started just before the COVID-19 pandemic and was somewhat overtaken by events as the issue of science informing policy became once again critical. The battles over what forms of evidence count, how evidence is often selectively presented and produces particular effects as it is circulated and consumed (or reduced and dismissed), have become central to how the pandemic and its aftermath have been experienced.

The key point of the Index and the collected texts (which can and should continue to grow) was not to provide definitive solutions to the question of evidence, nor was it to question the importance of evidence (or undermine the purpose of evidence-based policy). Instead, our aim was to highlight the diversity of data and methods that need to be brought together and thought alongside one another in order to construct good evidence. The project is necessarily emergent and has sought to allow contributors and readers to speculate on how re-thinking evidence (as a practice) might open up new opportunities for doing better work, for bringing narrative together with extensive data sets, for taking nonhierarchical approaches to data sources and forms, and in the process assembling new kinds of insight (something that clinicians regularly do in their day-to-day practice, for example). This was about opening up rather than closing things down, but, importantly, opening up in a more speculative way. Speculation has allowed writers the option to invent new ways of thinking about evidence - its production and relations. It bears repeating that the invitation of the project was not a way of suggesting that evidence is simply invented, but that we might discover new ways of producing better evidence and better relationships to evidence by loosening, temporarily, some of hierarchies and disciplinary forms that determine what can be indexed as evidence.

As the pandemic has developed, we have begun to see the Index as a space that might also track circulations of data and their appropriations. But the project's aim was never to argue particular points of evidence; rather, it was to stimulate interest in and increase understanding of how evidence emerges according to particular patterns and practices. While contributors are, as far as we can tell, committed to the shared project of improving how we think and do evidence, we felt it important to encourage them to experiment with the form and style of their contributions in order to open up the possibility of thinking and practising evidence otherwise. The team behind the Index of Evidence decided that it was important to peer review the contributions, however, to ensure that misinformation, disinformation, or points that were easily open to misinterpretation did not damage the scene of legitimate evidence.

So, the contributions are not about undermining the idea of evidence but finding ways to think about the problems of evidence: how to assemble it, how to narrate it, and how to 
protect it. The overarching theme of engaging with evidence as a concept and set of relations has meant that so far those most interested in contributing have been academic researchers. Contributors, some of whom are in earlier stages of their careers, have been enabled to write with a degree of experimental openness and frankness, without following conventional forms. While this open authorship, and the suggested openness to reading the entries, may be risky, given the stakes, we took the decision to retain an experimental feel to the Index rather than pre-script its outputs, intents, and audiences. True, the results may at this stage remain overly academic and are certainly geographically limited, but we hope that the Index can still raise some questions and perhaps offer glimpses of what an open assembly on evidence could produce. Part of the rationale for publishing an Open Letter was to introduce the project to a wider audience of potentially interested readers and contributors. The conceptual work to determine what can be learned from how the Index has developed - its successes and also its failures - will necessarily need to come later.

Given the nature of the letter and the intention of the work, which was to index a collective project on the fraught nature of evidence, we don't think it is useful at this stage to revise the text; doing so would be unlikely to resolve the valid reservations expressed concerning stakes, audience, and scope. And, as one of the reviewers notes, the nature of this piece was not well-fitted to the Wellcome Open's criteria of a) "Is the rationale for the Open Letter provided in sufficient detail? "b) "Does the article adequately reference differing views and opinions?" and c) Are all factual statements correct, and are statements and arguments made adequately supported by citations?" So rather than revise our original piece, we would hope that these views can instead be read alongside the Index and be used to stimulate more thoughts on the ways in which evidence might be assembled in future.

The Index of Evidence can be found at: https://www.indexofevidence.org

Steve Hinchliffe, Mike Michael, Laura Salisbury

Competing Interests: No competing interests were disclosed. 